\title{
PRODUÇÃO DE SERAPILHEIRA EM UMA FLORESTA DE Araucaria angustifolia (Bertol.) Kuntze NO MUNICÍPIO DE PINHAL GRANDE-RS ${ }^{1}$
}

\author{
Mauro Valdir Schumacher², Eleandro José Brun³ ${ }^{3}$ Jonas Inoé Hernandes ${ }^{4}$ e Flávia Gizele König 5
}

\begin{abstract}
RESUMO - O objetivo do trabalho foi avaliar a deposição anual de serapilheira, bem como a devolução de macronutrientes (N, P, K, Ca e Mg) em um povoamento de Araucaria angustifolia com 17 anos de idade, em Pinhal Grande-RS. O experimento foi instalado, de forma aleatória, em cinco parcelas de 10 x $20 \mathrm{~m}$. Em cada uma destas foram distribuídos, de forma sistemática, quatro coletores de madeira de $1 \mathrm{~m}^{2}$ de área. $\mathrm{O}$ material foi coletado mensalmente, durante um ano, e separado nas frações acículas e galhos, sendo, após seco em estufa e pesado em balança de precisão, moído e analisado quimicamente. A deposição de serapilheira foi de $6,96 \mathrm{Mg} / \mathrm{ha}$, sendo composta por $74 \%$ de acículas e $26 \%$ de galhos. Ocorreu uma marcante sazonalidade de deposição, com picos entre a primavera e o verão, diminuindo nos meses de outono e inverno, de acordo com a variação da precipitação média mensal. Acículas e galhos foram responsáveis por devolver ao piso florestal 84 e $16 \%$ do total dos nutrientes, que foi de $254,3 \mathrm{~kg} / \mathrm{ha}$. O cálcio foi o nutriente de maior devolução $(177,1 \mathrm{~kg} / \mathrm{ha})$. A quantidade expressiva de nutrientes devolvidos ao solo demonstra a importância da serapilheira na manutenção da capacidade produtiva do sítio.
\end{abstract}

Palavras-chave: Araucaria angustifolia, serapilheira e sustentabilidade.

\section{LITTERFALL IN AN Araucaria angustifolia (Bertol.) Kuntze FOREST IN PINHAL GRANDE, RS}

\begin{abstract}
The objective of this work was to evaluate the annual deposition of litter and macronutrient devolution $(\mathrm{N}, \mathrm{P}, \mathrm{K}, \mathrm{Ca}$ and $\mathrm{Mg})$ in a 17 year - old stand of Araucaria angustifolia in Pinhal Grande, RS. The experiment was arranged in a randomized design (5 plots of $10 \mathrm{~m} \times 20 \mathrm{~m}$ ). In each plot 4 wooder collectors of $1 \mathrm{~m}^{2}$ of area were systematically distributed. The material was collected monthly during one year and separated in needle and branch fractions, stove-dried and weighed in a precision balance, milled and analyzed chemically. Litter deposition was $6.96 \mathrm{Mg} / \mathrm{ha}$, composed by $74 \%$ needles and $26 \%$ branches. An outstanding deposition seasonality with deposition peacs between spring and summer was observed, decreasing towards the autumn and winter months, according to the average monthly precipitation. Needles and branches were responsible for the return to the forest floor of $84 \%$ and $16 \%$ of the total of the nutrients, which was 254,3 $\mathrm{kg} / \mathrm{ha}$. Calcium presented the highest devolution $(177.1 \mathrm{~kg} / \mathrm{ha})$. The expressive amount of nutrients returned to the soil demonstrates the importance of litter in maintaining productive local capacity.
\end{abstract}

Key words: $\quad$ Araucaria angustifolia, litter and sustainability.

1 Recebido para publicação em 14.11.2002 e aceito para publicação em 17.2.2004.

2 Engenheiro Florestal, Prof. Dr. do Departamento de Ciências Florestais - CCR/UFSM, Bolsista CNPq, Fone: (55)220-8444, Ramal 36, 97105-900 Santa Maria-RS, <schuma@ ccr.ufsm.br>; ${ }^{3}$ Engenheiro Florestal, Mestrando do Programa de Pós-graduação em Engenharia Florestal da UFSM, <eleandrojbrun@ @ahoo.com.br>. ${ }^{4}$ Engenheiro Florestal. ${ }^{5}$ Acadêmica do curso de graduação em Engenharia Florestal da UFSM. 


\section{INTRODUÇÃOO}

A produção de serapilheira e a devolução de nutrientes em ecossistemas florestais constituem a via mais importante do ciclo biogeoquímico (fluxo de nutrientes no sistema solo-planta-solo). Este ciclo, juntamente com o bioquímico (circulação de nutrientes no interior da planta), permite que as árvores da floresta possam sintetizar a matéria orgânica através da fotossíntese, reciclando principalmente os nutrientes em solos altamente intemperizados, onde a biomassa vegetal é o seu principal reservatório.

A produção seguida da decomposição da serapilheira é o principal meio de transferência dos nutrientes para o solo, possibilitando a sua reabsorção pelos vegetais vivos. Desta forma, a serapilheira torna-se um dos mais intensos sítios de interação entre a ciclagem de elementos químicos inorgânicos e a transferência de energia. A razão destes no complexo solo/folhedo condiciona a capacidade de produção do ecossistema (Delitti, 1984).

A queda das folhas é causada pela senescência, resultante de uma série de processos metabólicos ligados à fisiologia de cada espécie, e também pelos estímulos vindos do ambiente, como fotoperíodo, temperatura, estresse hídrico etc. (Kramer \& Kozlowski, 1960).

Em uma revisão em nível mundial, Bray \& Gorham (1964) concluíram que nas diferentes zonas macroecológicas, de modo geral, a quantidade de material orgânico depositado ao longo de um ano está relacionada com as condições climáticas, sendo menor nas regiões frias e maior nas equatoriais quentes e úmidas. Por exemplo, as florestas situadas em regiões árticas ou alpinas produzem, anualmente, cerca de $1,0 \mathrm{Mg} / \mathrm{ha}$ de serapilheira; as florestas temperadas frias, $3,5 \mathrm{Mg} / \mathrm{ha}$; as florestas temperadas quentes, $5,5 \mathrm{Mg} / \mathrm{ha}$; e as florestas equatoriais, cerca de $11,0 \mathrm{Mg} / \mathrm{ha}$.

A sazonalidade de deposição varia de espécie para espécie, nas regiões tropicais e subtropicais. Nas florestas de regiões temperadas e frias, a chegada do outono é o fenômeno que desencadeia o processo de derrubada total das folhas.

A deposição de serapilheira em povoamentos formados por espécies nativas, como a Araucaria angustifolia, é um dos aspectos primordiais a serem estudados na avaliação da nutrição mineral e ciclagem de nutrientes nessas florestas, com vistas ao planejamento do uso destas espécies para recuperação de áreas degradadas ou para produção de madeiras nobres (Poggiani \& Schumacher, 2000). A quantidade de serapilheira e seu conteúdo de nutrientes que são aportados ao solo pelo povoamento irão refletir na sua capacidade produtiva e no seu potencial de recuperação ambiental, tendo em vista as modificações que irão ocorrer nas características químicas do solo e, conseqüentemente, na cadeia alimentar resultante do material orgânico adicionado ao solo.

Backes et al. (2000) estudaram a deposição de serapilheira em florestas de araucária em São Francisco de Paula-RS e constataram que esta foi mais concentrada entre a primavera e o verão, ao contrário de florestas latifoliadas, que geralmente concentram a maior deposição mais cedo, entre o fim do inverno e o começo da primavera.

De acordo com Fernandes \& Backes (1998), nas florestas nativas de araucária na Floresta Nacional de São Francisco de Paula-RS, a contribuição da araucária na serapilheira é maior que a do restante da vegetação, tanto para estruturas vegetativas como reprodutivas, entretanto os períodos de maior queda de material são diferenciados: enquanto no verão e no outono a contribuição da araucária varia de $85-67 \%$, no inverno e na primavera varia de 70-46\%. De forma inversa, as latifoliadas contribuem com 33-15\% durante o verão e o outono e com 54-30\% durante o inverno e primavera.

Brun et al. (2001), estudando a deposição de serapilheira em três fases sucessionais de uma Floresta Estacional Decidual em Santa Tereza-RS, relataram que o estádio sucessional mais velho (floresta madura) diferenciou com maior nitidez dois períodos, com elevadas deposições entre os meses de setembro e fevereiro e menores entre os meses de março a agosto. Os estádios sucessionais mais jovens (capoeirão e floresta secundária) demonstraram a mesma tendência, porém com maiores variações dentro de cada período. De acordo com os autores, o aumento na deposição de serapilheira ocorrido na primavera pode estar relacionado à detenção do crescimento provocada pelo inverno, que se manifesta à medida que a diferença P-ETP se eleva a partir de julho.

Schumacher (1992), analisando aspectos da ciclagem de nutrientes em talhões de três espécies de eucalipto localizados em Anhembi-SP, observou que as três espécies apresentavam comportamento diferenciado quanto à sazonalidade da deposição de folhedo ao longo das diferentes estações do ano. Concluiu que os resultados 
obtidos não podem ser explicados somente pelas correlações existentes entre a deposição de folhedo e as variáveis meteorológicas como temperatura e precipitação, pois todos os fatores, sejam eles climáticos, edáficos e genéticos, precisam ser analisados no contexto geral, para poder explicar as características da deposição de folhedo pertinentes a cada espécie.

O objetivo do presente trabalho foi avaliar a produção de serapilheira e o aporte de nutrientes ao solo por esta via, bem como fazer inferências a respeito do efeito da temperatura e da precipitação média mensal nestes eventos, em um povoamento de Araucaria angustifolia com 17 anos de idade, no município de Pinhal Grande-RS.

\section{MATERIAL E MÉTODOS}

O estudo foi desenvolvido em um povoamento de Araucaria angustifolia com 17 anos de idade, plantado em espaçamento de $2 \times 2 \mathrm{~m}$, no município de Pinhal Grande-RS. A área experimental localiza-se entre as coordenadas geográficas 29 e $30^{\circ}$ de latitude sul e $53^{\circ}$ e $54^{\circ}$ de longitude oeste. Na região predomina solos do tipo Argissolo Vermelho-Amarelo (Streck et al., 1999). O clima, pela classificação de Köppen, é do tipo Cfa, subtropical, onde a temperatura do mês mais quente é superior a $22^{\circ} \mathrm{C}$ e a do mês mais frio oscila entre -3 e $18{ }^{\circ} \mathrm{C}$. A temperatura média do mês mais quente (janeiro) e a temperatura média anual são, respectivamente, 22,7 e $17,6^{\circ} \mathrm{C}$. A precipitação pluviométrica anual varia entre 1.700 e $1.800 \mathrm{~mm}$ (Moreno, 1961).

Por ocasião da implantação do povoamento, em 1981, o terreno recebeu aração e gradagem em área total, sem haver nenhum tipo de adubação. Foram plantadas três sementes de Araucaria angustifolia por cova, visando a seleção da planta de maior porte, após a sua emergência, através de um raleio. Até o segundo ano foram realizados roçadas e combate a formigas-cortadeiras.

O experimento foi implantado em outubro de 1998, sendo o delineamento estatístico o inteiramente casualizado, com cinco parcelas de $10 \times 20 \mathrm{~m}$, e nestas, de forma sistemática, foram distribuídos quatro coletores (unidades amostrais), totalizando 20. Dentro de cada parcela, um coletor foi instalado entre quatro árvores, outro na linha de plantio, outro na coluna (na entrelinha entre duas árvores) e o último encostado ao tronco de um indivíduo (Figura 1).

Para quantificação da devolução de serapilheira (galhos e acículas) foram confeccionados coletores de
$1 \mathrm{~m}^{2}$ de área, formados por tela de náilon com malha de $1 \mathrm{~mm}$, presa a uma moldura de madeira com borda de $15 \mathrm{~cm}$ de altura, suspensa a $70 \mathrm{~cm}$ do solo por estacas. $\mathrm{O}$ material depositado sobre os coletores foi recolhido mensalmente e levado ao Laboratório de Ecologia Florestal, pertencente ao Departamento de Ciências Florestais da Universidade Federal de Santa Maria, onde primeiramente foi separado nas frações galhos e acículas, sendo então colocado para secar em estufa com circulação e renovação de ar a $75^{\circ} \mathrm{C}$, até alcançar massa seca constante, e que foi aferida em balança de precisão $(0,01 \mathrm{~g})$. Através da quantidade média de serapilheira encontrada nos coletores, foi estimada a biomassa devolvida mensal e anualmente, em kg/ha/ano, para o piso florestal.

Para determinação da concentração de N, P, K, Ca e Mg nas frações da serapilheira, foram tomadas alíquotas do material coletado mensalmente. Este material foi moído em moinho tipo Wiley, com peneira de 30 mesh, e posteriormente analisado de acordo com a metodologiapadrão do Laboratório de Ecologia Florestal, descrita em Tedesco et al. (1995).

A análise de dados foi realizada através do Programa Microsoft Excel v. 7.0. Os coeficientes de correlação apresentados foram calculados com base na equação do coeficiente de correlação de Pearson, com probabilidade de 5\%.

\section{RESULTADOS E DISCUSSÃO}

\subsection{Produção de Serapilheira}

A produção total de serapilheira no povoamento de Araucaria angustifolia com 17 anos de idade alcançou $6,96 \mathrm{Mg} / \mathrm{ha}$, sendo ela formada por $26,3 \%$ de galhos e $73,7 \%$ por acículas. Este resultado encontra-se dentro do intervalo estabelecido por Bray \& Gorham (1964), para as latitudes entre 29 e $30^{\circ} \mathrm{S}$.

Essa produção foi inferior a de um plantio de araucária com 45 anos de idade, em São Francisco de Paula-RS, que foi de 7,90 Mg/ha (Backes et al., 2000). Britez et al. (1992), estudando uma área de Floresta Ombrófila Mista em São Mateus do Sul-PR, relataram uma produção de serapilheira muito semelhante à deste estudo, igual a 6,53 Mg/ha. Koehler et al. (1987), estudando a produção de serapilheira de povoamentos de Araucaria angustifolia em três diferentes sítios no Paraná, constataram valores iguais a $5,8 \mathrm{Mg} / \mathrm{ha} /$ ano em sítio de boa qualidade, $6,4 \mathrm{Mg} / \mathrm{ha} / \mathrm{ano}$ em sítio de média qualidade e $5,0 \mathrm{Mg} / \mathrm{ha} / \mathrm{ano}$ em sítio de baixa qualidade.

R. Árvore, Viçosa-MG, v.28, n.1, p.29-37, 2004 
A sazonalidade da deposição de serapilheira durante o período de estudo é observada na Figura 2, que ilustra o comportamento da queda de serapilheira entre os meses de outubro de 1998 e setembro de 1999. Observou-se aumento na produção de serapilheira a partir do mês de dezembro, atingindo um valor próximo de 1,0 t/ha no mês de janeiro de 1999. Durante este último período podem ser destacados picos de deposição nos meses de abril e setembro.

A maior deposição de serapilheira se deu nos meses de primavera/verão, associada às maiores precipitações pluviométricas. A sazonalidade de deposição no povoamento de A. angustifolia esteve ligada às variações climáticas, de forma que ocorreu boa correlação de Pearson entre a deposição de serapilheira e a precipitação média mensal $(r=0,43 ; p=0,05)$.

Segundo Backes et al. (2000), a maior queda de acículas de araucária ocorre durante os meses de primavera e verão, devendo ser ressaltado que povoamentos da espécie têm a tendência de devolver mais material na primavera e formações nativas no verão. No estudo realizado por Britez et al. (1992), pôde-se constatar que a maior queda de serapilheira ocorreu na primavera, quando do aumento da pluviosidade e da temperatura. Fernandes \& Backes (1998) demonstraram aspecto um tanto diferenciado, com maior deposição ocorrendo mais tarde, entre o verão e o outono.

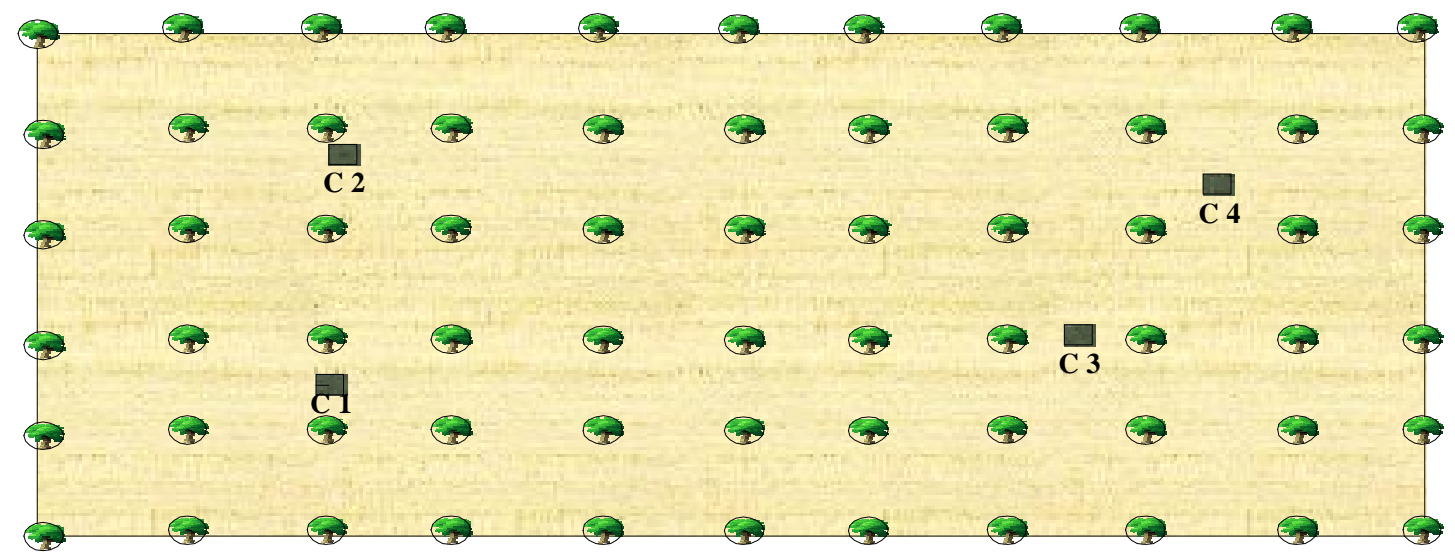

Figura 1 - Croqui demonstrativo da distribui ção dos col etores de serapil heira dentro de cada parcela al eatória no povoamento. Figure 1 - Distribution of litter collectors inside each randomized pl ot in the stand.

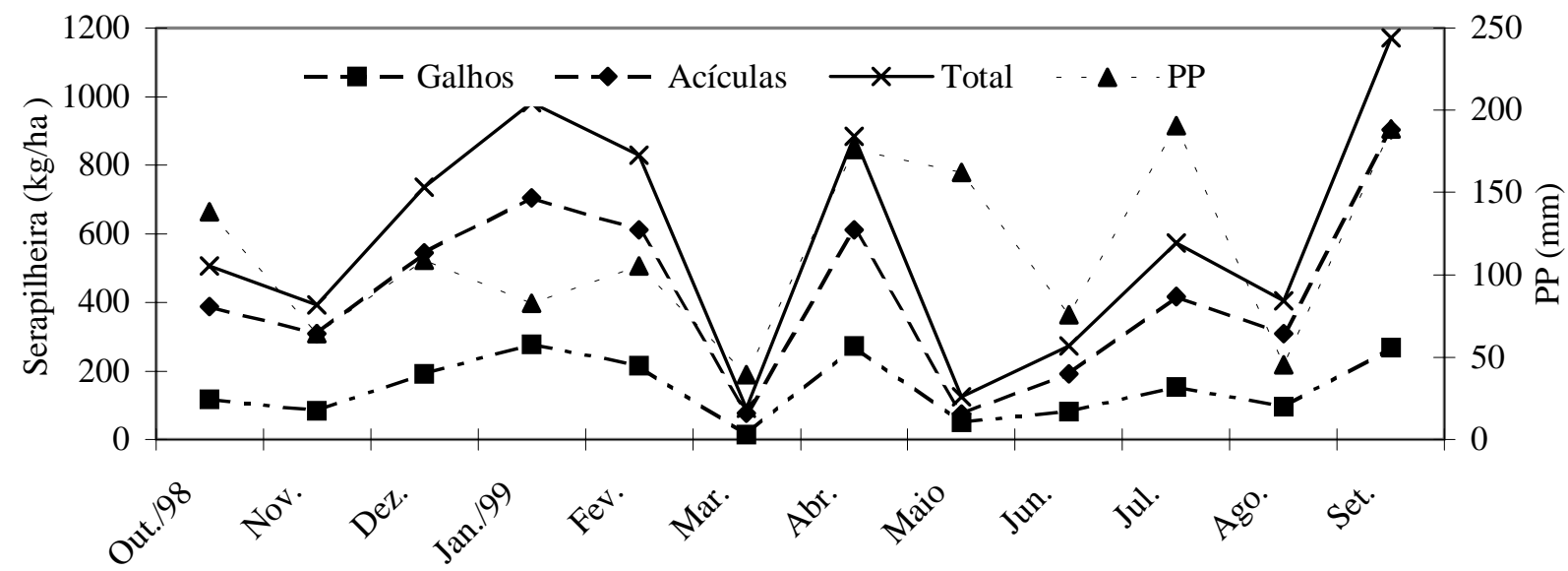

Figura 2 - Deposição de serapilheira (kg/ha) em povoamento de Araucaria angustifolia aos 17 anos de idade. Pinhal Grande-RS. Figure 2 - Litterfall (kg/ ha) in Araucaria angustifolia stand at 17 years of age. Pinhal Grande, RS. 
Dias \& Oliveira Filho (1997) relataram que a variação na queda de serapilheira é esperada em virtude das diferenças nas condições ambientais, principalmente de pluviosidade. Estes autores encontraram, para uma Floresta Estacional Semidecídua, em Lavras-MG, maior deposição de serapilheira no período de menor déficit hídrico, na estação chuvosa.

Em uma formação florestal subtropical na Austrália, Lowman (1988) constatou uma diferença significativa entre a produção de serapilheira de 4 anos consecutivos, fato atribuído à grande variação na pluviosidade e ao padrão das tempestades, seguidas de queda de material lenhoso.

Em regiões tropicais e subtropicais a distribuição das chuvas é, em grande parte, responsável pela deposição de folhedo, ao contrário das regiões frias, onde a chegada do outono desencadeia o processo de derrubada das folhas. Poggiani \& Monteiro Júnior (1990) observaram maior deposição de serapilheira nos períodos de menor pluviosidade, em uma Floresta Estacional Semidecídua em Piracicaba-SP. Leitão Filho (1993) e Jackson (1978), trabalhando em áreas de Floresta Ombrófila Densa localizadas em Cubatão-SP e Santa Teresa ES, respectivamente, encontraram maior queda de serapilheira nos meses de dezembro e janeiro, tendo a curva de deposição do folhedo seguido mais ou menos a curva de precipitação e evapotranspiração potencial.

Ao que tudo indica, o padrão de deposição de serapilheira para o povoamento plantado de araucária em questão é diferenciado quanto às florestas exclusivamente de latifoliadas do Sul do Brasil, de forma que o pico de deposição ocorre mais tarde, entre a primavera e o verão, e não desde o final do inverno até a primavera, como geralmente ocorre nestas últimas. Entre os fatores que podem ser determinantes para que tal fenômeno ocorra estão o regime de precipitação, as variações anuais de temperatura e o fato de a floresta ser formada por uma única espécie, de modo que a deposição de serapilheira reflete suas características exclusivamente.

\subsection{Nutrientes na Serapilheira}

O Quadro 1 apresenta a concentração média anual de nutrientes nas frações galhos e acículas da serapilheira amostrada no povoamento. A fração acículas apresentouse sempre mais rica em nutrientes do que a fração galhos, exceto para o K. Quanto ao N, a diferença entre a sua concentração nas duas frações foi grande, demonstrando ocorrer nos galhos um baixo teor do elemento. $\mathrm{O}$ nutriente mais freqüente em ambas as frações foi o cálcio, com concentrações muito superiores às dos demais elementos.

O teor de nutrientes na serapilheira pode variar, para uma mesma espécie, em função do sítio, das características da planta e das do próprio elemento, o que torna difícil a comparação entre diferentes povoamentos. Carpanezzi (1980) analisou dados provenientes de 20 diferentes ecossistemas de folhosas de várias partes do mundo, obtendo as seguintes médias para a concentração de macronutrientes, em $\mathrm{g} / \mathrm{kg}: \mathrm{N}=12,0, \mathrm{P}=0,79$, $\mathrm{K}=5,9, \mathrm{Ca}=13,4$ e $\mathrm{Mg}=3,1$. As médias do Quadro 1 demonstram que o teor de $\mathrm{N}$ está bem abaixo da média estipulada pelo referido autor, fato que também ocorre para $\mathrm{K}$ e $\mathrm{Mg}$, enquanto o $\mathrm{P}$ apresenta valores próximos e o Ca, superiores. A concentração de cálcio pode ser explicada pelo fato de este elemento apresentar baixa mobilidade no tecido vegetal e estar associado à lignificação e constituição de paredes celulares.

Fernandes \& Backes (1998) constataram que as latifoliadas do estrato secundário, em floresta natural de araucária, contêm maiores quantidades de cinzas do que a araucária, portanto o retorno de elementos minerais, por parte destas últimas, é menor que nas latifoliadas.

Quadro 1 - Concentração média anual \pm desvio-padrão para os nutrientes nas diferentes frações da serapilheira amostrada em povoamento de Araucaria angustifolia aos 17 anos de idade. Pinhal Grande-RS

Table 1 - Annual average concentration \pm deviation pattern for the nutrients in the different litter fractions in the Araucaria angustifolia stand at 17 years of age. Pinhal Grande, RS

\begin{tabular}{|l|c|c|c|c|c|}
\hline \multirow{2}{*}{ Fração } & \multicolumn{5}{|c|}{ Nutriente $(\mathrm{g} / \mathrm{kg})$} \\
\cline { 2 - 6 } & $\mathrm{N}$ & $\mathrm{P}$ & $\mathrm{K}$ & $\mathrm{Ca}$ & $\mathrm{Mg}$ \\
\hline Acículas & $9,87 \pm 0,78$ & $0,80 \pm 0,35$ & $1,45 \pm 0,41$ & $28,16 \pm 3,16$ & $1,24 \pm 0,37$ \\
\hline Galhos & $0,89 \pm 0,33$ & $0,62 \pm 0,34$ & $2,01 \pm 0,87$ & $17,80 \pm 3,59$ & $1,18 \pm 0,39$ \\
\hline
\end{tabular}


Em trabalhos onde o teor de nutrientes é avaliado nas diferentes frações de serapilheira, geralmente são constatadas concentrações maiores nas acículas do que nos galhos (Koehler et al., 1987), o que pode variar somente em relação ao $\mathrm{Ca}$, que pode estar eventualmente mais concentrado nos galhos (Britez et al., 1992).
Na Figura 3 pode-se observar a variação na concentração média mensal de nutrientes nas frações galhos e acículas da serapilheira de araucária. $O$ nitrogênio e $o$ cálcio não apresentaram grandes variações em sua concentração durante $o$ ano, a não ser quanto à concentração de $\mathrm{Ca}$ nos galhos, que apresentou picos nos meses de
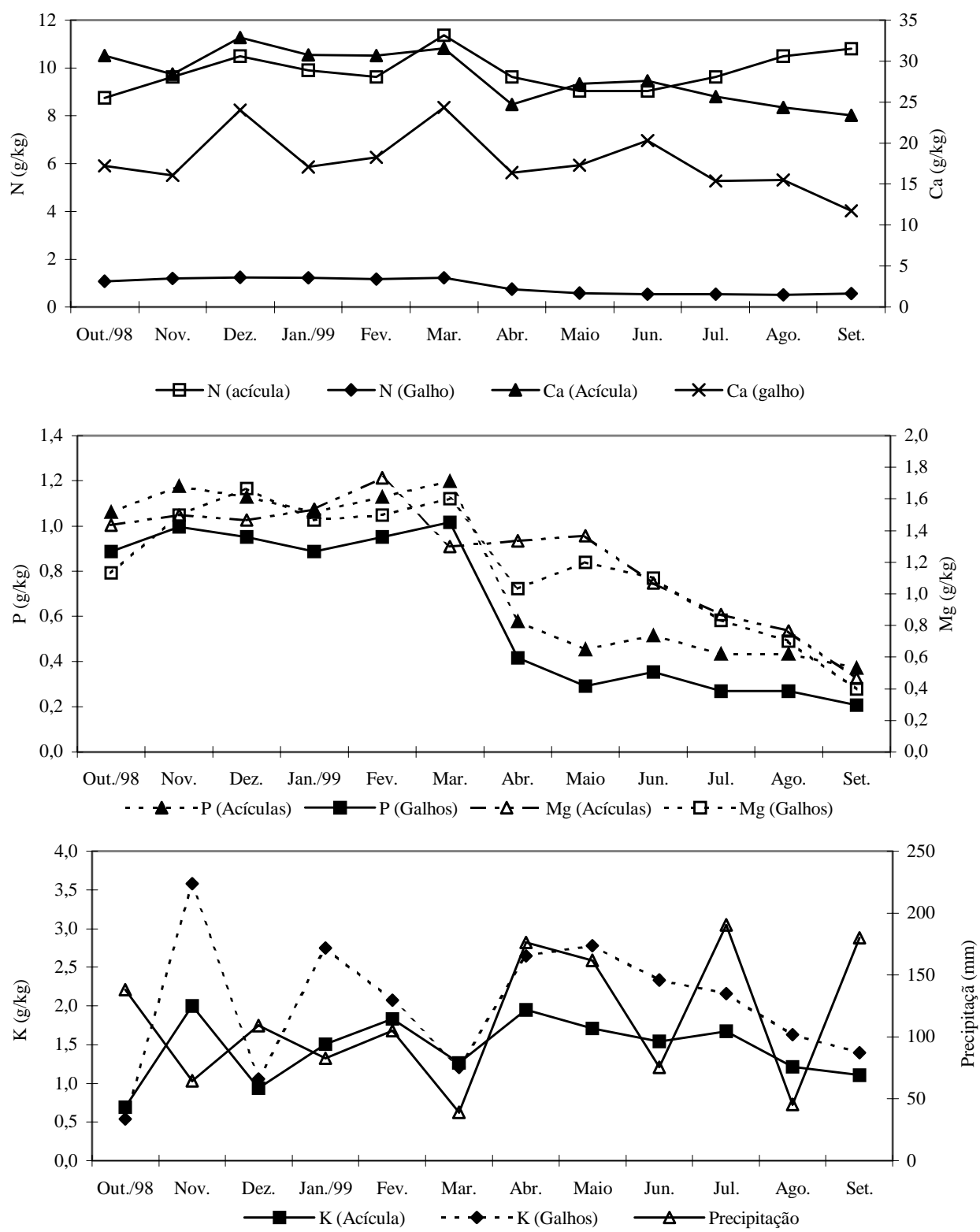

Figura 3 - Concentração anual de N, P, K, Ca e Mg (g/kg) nas frações acículas e gal hos da serapilheira de um povoamento de Araucaria angustifolia aos 17 anos de idade. Pinhal Grande-RS.

Figure 3 - Annual concentrations of $\mathrm{N}, \mathrm{P}, \mathrm{K}, \mathrm{Ca}$ e $\mathrm{Mg}(\mathrm{g} / \mathrm{kg})$ in the litter needle and branch fractions in an a 17-year-old Araucaria angustifolia stand. Pinhal Grande, RS. 
dezembro, março e junho. O P e o Mg apresentaram maiores concentrações na primavera e no verão, diminuindo visivelmente no inverno. O potássio apresentou concentrações bastante variáveis durante o ano, principalmente nos galhos, não apresentando nenhuma sazonalidade nítida na sua concentração.

O fósforo é um elemento constituinte de compostos ricos de energia, sendo altamente móvel na planta, portanto facilmente retranslocado dos tecidos mais velhos para os mais jovens da planta. A presença do magnésio está associada com a presença do fósforo, pois ele é essencial para a absorção deste último (Ferri, 1985).

De acordo com Cunha et al. (1993), o potássio apresenta comportamento distinto dos demais nutrientes em relação à variação mensal da sua concentração, que varia bastante durante o ano, geralmente ocorrendo menores concentrações nos períodos de maior precipitação pluviométrica.

No Quadro 2 observa-se que a temperatura influenciou de forma significativa a concentração de $\mathrm{P}, \mathrm{Ca}$ e $\mathrm{Mg}$ nas acículas, e destes mais o $\mathrm{N}$ nos galhos. Conclui-se daí que a concentração de elementos na serapilheira aumenta significativamente no verão, principalmente devido à maior atividade fisiológica das plantas em tal período, o que resulta em maiores taxas de alocação de nutrientes no período de maior crescimento vegetativo e, conseqüentemente, em maior deposição do material orgânico acumulado anteriormente.

Quanto à precipitação, podem ser percebidas correlações negativas com a concentração de $\mathrm{P}$ e Ca nas acículas e de N, P, Ca e Mg nos galhos, o que resulta em aumento na concentração destes elementos em períodos de menor precipitação. Este comportamento é geralmente esperado para o K, em virtude de ele ser componente do suco celular e facilmente lixiviável com a chuva, o que não pode ser observado via correlação. Tal aspecto pode ser visualizado na Figura 2.

Segundo Veneklass (1991), a diferença na concentração de elementos minerais, nas diferentes frações, está baseada, em grande parte, na estrutura dos tecidos que predominam nos diferentes órgãos da planta.

O Quadro 3 apresenta a transferência anual de nutrientes ao solo via serapilheira. $\mathrm{O} \mathrm{Ca}$ foi o elemento transferido ao solo em maior quantidade, seguido pelo N. A magnitude de transferência dos nutrientes ao solo foi: $\mathrm{Ca}>\mathrm{N}>\mathrm{K}>\mathrm{Mg}>\mathrm{P}$. As acículas foram as principais responsáveis pela devolução de nutrientes ao solo.

Quadro 2 - Coeficiente de correlação de Pearson entre a variação mensal na concentração de nutrientes nas frações de serapilheira e algumas variáveis meteorológicas

Table 2 - Pearson Correlations Coefficient between monthly variation of nutrient concentrations in the litter fractions and some meteorological variables

\begin{tabular}{|c|c|c|c|c|c|c|}
\hline Variável & Fração & $\mathrm{N}$ & $\mathrm{P}$ & $\mathrm{K}$ & $\mathrm{Ca}$ & $\mathrm{Mg}$ \\
\hline Precipitação (mm) & \multirow{2}{*}{ Acículas } & $-0,33$ & $-0,51$ & 0,06 & $-0,43$ & $-0,25$ \\
\hline Temperatura $\left({ }^{\circ} \mathrm{C}\right)$ & & 0,19 & $\mathbf{0 , 8 9}$ & 0,01 & 0,75 & $\mathbf{0 , 7 9}$ \\
\hline Precipitação (mm) & \multirow{2}{*}{ Galhos } & $-0,43$ & $-0,50$ & $-0,02$ & $-0,50$ & $-0,48$ \\
\hline Temperatura $\left({ }^{\circ} \mathrm{C}\right)$ & & 0,94 & $\mathbf{0 , 8 9}$ & 0,02 & 0,43 & $\mathbf{0 , 8 0}$ \\
\hline
\end{tabular}

Obs: os campos com correlações altas ( $\mathrm{r} \quad 0,6)$ e médias $(0,4 \quad \mathrm{r}<0,6)$ estão sombreados. As correlações são significativas a $5 \%$ de probabilidade de erro.

Quadro 3 - Transferência anual de N, P, K, Ca e Mg pelas frações de serapilheira $(\mathrm{kg} / \mathrm{ha})$ no povoamento de Araucaria angustifolia aos 17 anos. Pinhal Grande-RS

Table 3 - Annual transference of $\mathrm{N}, \mathrm{P}, \mathrm{K}, \mathrm{Ca}$ and $\mathrm{Mg}$ by the litter fractions (kg/ ha) in the 17-year-old Araucaria angustifolia stand. Pinhal Grande, RS

\begin{tabular}{|l|c|c|c|c|c|c|c|c|c|c|c|}
\hline \multicolumn{1}{|c|}{ Fração } & Peso & $\mathrm{N}$ & $\%$ & $\mathrm{P}$ & $\%$ & $\mathrm{~K}$ & $\%$ & $\mathrm{Ca}$ & $\%$ & $\mathrm{Mg}$ & $\%$ \\
\hline Acículas & 5140 & 50,7 & 96,9 & 4,1 & 78,8 & 7,5 & 67,0 & 144,7 & 81,7 & 6,4 & 75,3 \\
\hline Galhos & 1820 & 1,6 & 3,1 & 1,1 & 21,2 & 3,7 & 33,0 & 32,4 & 18,3 & 2,1 & 24,7 \\
\hline Total & 6960 & 52,3 & 100 & 5,2 & 100 & 11,2 & 100 & 177,1 & 100 & 8,5 & 100 \\
\hline
\end{tabular}


Koehler \& Reissmann (1992) também relataram que o principal elemento retornado ao solo via serapilheira de araucária foi o Ca, seguido pelo N. Backes et al. (2000) relataram que a quantidade de nutrientes retornados ao solo via serapilheira foi de $302,4 \mathrm{~kg} / \mathrm{ha}$ em floresta nativa e $298,4 \mathrm{~kg} / \mathrm{ha}$ em floresta plantada de araucária, com 45 anos de idade.

\section{CONCLUSÕES}

A produção de serapilheira encontrada neste estudo é considerada alta, quando comparada com a de povoamentos de araucária de maior idade. Condições apropriadas de sítio podem estar auxiliando a ocorrência do fato, o que é de grande importância em plantios puros com espécies madeireiras, pois através da serapilheira, além do fornecimento de nutrientes ao solo, têm-se outros benefícios, como a proteção do solo contra a erosão, entre outros.

No povoamento estudado, a serapilheira foi devolvida ao solo de forma sazonal, apresentando os maiores picos de deposição entre a primavera e o verão e uma produção menor nos meses de outono e inverno, seguindo uma curva concomitante com a precipitação média mensal.

As maiores concentrações de elementos químicos foram encontradas nas acículas, menos para o potássio, que apresentou concentração superior nos galhos. Tal fato faz com que as acículas sejam a principal fração da serapilheira, tanto em massa seca devolvida ao solo como na concentração de nutrientes. Esta fração representa cerca de $74 \%$ da massa seca de serapilheira e $80 \%$ dos nutrientes retornados ao solo anualmente.

O total de nutrientes retornados ao solo em função da deposição da serapilheira foi de 254,3 kg/ha. Esta expressiva quantidade reflete a importância da serapilheira na manutenção da sustentabilidade do ecossistema. Em povoamentos plantados, a serapilheira representa ganhos nutricionais significativos que irão contrabalançar no final da rotação, quando da extração de grande quantidade de biomassa e nutrientes do sítio.

\section{REFERÊNCIAS BIBLIOGRÁFICAS}

BACKES, A.; FERNANDES, A. V.; ZENI, D. J. Produção de folhedo em uma floresta com Araucaria angustifolia no sul do Brasil. Revista de Pesquisas - Botânica, v. 50, p. $97-117,2000$.

R. Árvore, Viçosa-MG, v.28, n.1, p.29-37, 2004
BRAY, J. R.; GORHAM, E. Litter production in forest of the world. Advances in Ecological Research, v. 2, p. 101-157, 1964.

BRITEZ, R. M. et al. Deposição estacional de serapilheira e macronutrientes em uma floresta de araucária, São Mateus do Sul, PR. In: CONGRESSO NACIONAL SOBRE ESSÊNCIAS NATIVAS, 2., 1992, São Paulo: Revista do Instituto Florestal, v. 4, p. 766-772, 1992 (Edição Especial).

BRUN, E. J. et al. Relação entre a produção de serapilheira e variáveis meteorológicas em três fases sucessionais de uma Floresta Estacional Decidual no RS. Revista Brasileira de Agrometeorologia, v. 9, n. 2, p. 277-285, 2001.

CARPANEZZI, A. A. Deposição de material orgânico e nutrientes em uma floresta natural e em uma plantação de eucalipto no interior do estado de São Paulo. 1980. $107 \mathrm{f}$. Dissertação (Mestrado em Engenharia Florestal) - Escola Superior de Agricultura “Luiz de Queiroz”, Piracicaba, 1980.

CUNHA, G. C. et al. Dinâmica nutricional em floresta estacional decidual com ênfase aos minerais provenientes da deposição da serapilheira. Ciência Florestal, v. 3, n. 1, p. 35-64, 1993.

DELITTI, W. B. C. Aspectos comparativos da ciclagem de nutrientes minerais na mata ciliar, no campo cerrado e na floresta implantada de Pinus elliottii var. elliottii. 1984. $248 \mathrm{f}$. Tese (Doutorado em Ecologia Vegetal) - Instituto de Botânica, Universidade de São Paulo, São Paulo, 1984.

DIAS. H. C. T.; OLIVEIRA FILHO, A. T. Variação temporal e espacial da produção de serapilheira em uma floresta estacional semidecídua Montana em Lavras, MG. Revista Árvore, v. 21, n. 1, p. 11-26. 1997.

FERNANDES, A. V.; BACKES, A. Produtividade primária em floresta com Araucaria angustifolia no Rio Grande do Sul. Iheringia - Série Botânica, v. 51, n. 1, p. 63-78, 1998.

FERRI, M. G. Fisiologia vegetal. São Paulo: EPU, 1985. $365 \mathrm{p}$.

JACKSON, J. F. Seasonality of flowering and leaf-fall in a Brazilian Subtropical Lower Montane Moist Forest. Biotropica, v. 10, n. 1, p. 38-42, 1978.

KOEHLER, C. W.; REISSMANN, C. B. Macronutrientes retornados com a serapilheira Araucaria angustifolia em função do sítio. In: CONGRESSO NACIONAL SOBRE ESSÊNCIAS NATIVAS, 2., 1992, São Paulo: Revista do Instituto Florrestal, v. 4, p. 645-648, 1992. (Edição Especial). 
KOEHLER, C. W.; REISSMANN, C. B.; KOEHLER, H. S. Deposição de resíduos orgânicos (serapilheira) e nutrientes em plantio de Araucaria angustifolia em função do sítio.

Revista do Setor de Ciências Agrárias, v. 9, p. 89-96, 1987.

KRAMER, R. J.; KOSLOWSKI, T. T. Fisiologia das árvores. Trad. de Antonio M. A. Magalhães. Lisboa: Fundação Kalouste Gouldbenkian, 1960. 745 p.

LEITÃO FILHO, H. F. (Coord.). Ecologia da mata atlântica em Cubatão (SP). São Paulo: Universidade Estadual Paulista, 1993. 184 p.

LOWMAN, M. D. Litterfall and litter decay in three Australian rainforest formations. Journal of Ecology, n. 76, p. $451-465,1988$.

MORENO, J. A. Clima do Rio Grande do Sul. Porto Alegre: Secretaria da Agricultura, 1961. 73 p.

POGGIANI, F.; SCHUMACHER M. V. Ciclagem de nutrientes em Florestas Nativas. In: GONÇALVES, J. L. M.; BENEDETTI, V. (Ed.) Nutrição e Fertilização Florestal. Piracicaba: IPEF/ESALQ - USP. 2000. $427 \mathrm{p}$.
POGGIANI, F.; MONTEIRO JR.; E. S. Deposição de folhedo e retorno de nutrientes ao solo numa Floresta Estacional Semidecídua em Piracicaba, SP. In: CONGRESSO FLORESTAL BRASILEIRO, 6., 1990, Campos do Jordão. Trabalhos Voluntários... Campos do Jordão, 1990. p. 596-602.

SCHUMACHER, M. V. Aspectos da ciclagem de nutrientes e do microclima em talhões de Eucalyptus camaldulensis Dehnh., Eucalyptus grandis W. Hill ex Maiden e Eucalyptus torelliana F. Muell. 1992. 87 f. Dissertação (Mestrado em Engenharia Florestal) - Universidade de São Paulo, 1992.

STRECK, E. V.; KAMPF, N.; KLAMT, E. Atualização da classificação taxonômica das unidades de levantamento de reconhecimento dos solos do estado do Rio Grande do Sul. Boletim informativo da EMATER, v. 16, n. 9, 1999. Série Solos.

TEDESCO, M. J. et al. Análise de solo, plantas e outros materiais. Porto Alegre: Departamento de Solos - UFRGS, 1995. 118 p. (Boletim Técnico).

VENEKLASS, E. J. Litterfall and nutrient fluxes in two montane tropical rain forests, Colômbia. Journal of Tropical Ecology, v. 7, p. 319-336. 1991. 